\title{
Glucagon-Like Peptide-1 Receptor Activation in the Nucleus Accumbens Core Suppresses Feeding by Increasing Glutamatergic AMPA/Kainate Signaling
}

\author{
Elizabeth G. Mietlicki-Baase, ${ }^{1}$ Pavel I. Ortinski, ${ }^{2,4}$ David J. Reiner, ${ }^{1}$ Christopher G. Sinon, ${ }^{3}$ James E. McCutcheon, ${ }^{3}$ \\ R. Christopher Pierce, ${ }^{2}$ Mitchell F. Roitman, ${ }^{3}$ and Matthew R. Hayes ${ }^{1}$ \\ ${ }^{1}$ Translational Neuroscience Program and ${ }^{2}$ Center for Neurobiology and Behavior, Department of Psychiatry, Perelman School of Medicine at the \\ University of Pennsylvania, Philadelphia, Pennsylvania 19104, ${ }^{3}$ Department of Psychology, University of Illinois at Chicago, Chicago, Illinois 60607, and \\ ${ }^{4}$ Department of Pharmacology, Physiology, and Neuroscience, University of South Carolina, Columbia, South Carolina 29209
}

Glucagon-like peptide-1 receptor (GLP-1R) activation in the nucleus accumbens (NAc) core is pharmacologically and physiologically relevant for regulating palatable food intake. Here, we assess whether GLP-1R signaling in the NAc core of rats modulates GABAergic medium spiny neurons (MSNs) through presynaptic-glutamatergic and/or presynaptic-dopaminergic signaling to control feeding. First, ex vivo fast-scan cyclic voltammetry showed that the GLP-1R agonist exendin-4 (Ex-4) does not alter dopamine release in the NAc core. Instead, support for a glutamatergic mechanism was provided by ex vivo electrophysiological analyses showing that Ex-4 activates presynaptic GLP-1Rs in the NAc core to increase the activity of MSNs via a glutamatergic, AMPA/kainate receptor-mediated mechanism, indicated by increased mEPSC frequency and decreased paired pulse ratio in core MSNs. Only a small, direct excitatory effect on MSNs by Ex-4 was observed, suggesting that the contribution of postsynaptic GLP-1R to MSN activity is minimal. The behavioral relevance of the electrophysiological data was confirmed by the finding that intracore injection of the AMPA/kainate receptor antagonist CNQX attenuated the ability of NAc core GLP-1R activation by Ex-4 microinjection to suppress food intake and body weight gain; in contrast, intracore NMDA receptor blockade by AP-5 did not inhibit the energy balance effects of NAc core Ex-4. Together, these data provide evidence for a novel glutamatergic, but not dopaminergic, mechanism by which NAc core GLP-1Rs promote negative energy balance.

Key words: diabetes; dopamine; energy balance; mesolimbic; obesity; VTA

\section{Introduction}

The incretin hormone glucagon-like peptide-1 (GLP-1) is produced peripherally by L-cells of the distal small intestine, and centrally by neurons in the nucleus tractus solitarius (NTS; Holst, 2007). NTS GLP-1-producing neurons project throughout the brain to many nuclei relevant for energy balance regulation, including mesolimbic reward system (MRS) nuclei such as the ventral tegmental area (VTA) and the nucleus accumbens (NAc; Dossat et al., 2011; Alhadeff et al., 2012). While GLP-1 receptor (GLP-1R) activation in these MRS sites is pharmacologically and physiologically relevant for the control of palatable food intake (Dossat et al., 2011; Alhadeff et al., 2012), the physiological and

Received Jan. 10, 2014; revised April 11, 2014; accepted April 15, 2014.

Author contributions: E.G.M.-B., P.I.O., J.E.M., R.C.P., M.F.R., and M.R.H. designed research; E.G.M.-B., P.I.O., D.J.R., C.G.S., and J.E.M. performed research; E.G.M.-B., P.I.O., D.J.R., C.G.S., J.E.M., M.F.R., and M.R.H. analyzed data; E.G.M.-B., P.I.O., D.J.R., J.E.M., R.C.P., M.F.R., and M.R.H. wrote the paper.

This research was supported by National Institutes of Health research grants DK097954 (E.G.M.-B.); DA031747 (P.I.O.); DA033641, DA022339, and DA018678 (R.C.P.); DA025634 (M.F.R.); and DK096139 and DK085435 (M.R.H.). Valuable technical assistance was provided by Diana Olivos and Lauren McGrath, and constructive advice was provided by Heath Schmidt and Amber Alhadeff.

The authors declare no competing financial interests.

Correspondence should be addressed to either Dr. Elizabeth G. Mietlicki-Baase or Dr. Matthew R. Hayes, 125 South 31st Street, Philadelphia, PA 19104. E-mail: ebaase@mail.med.upenn.edu or hayesmr@mail.med.upenn.edu.

DOI:10.1523/JNEUROSCI.0115-14.2014

Copyright $\odot 2014$ the authors $\quad 0270-6474 / 14 / 346985-08 \$ 15.00 / 0$ behavioral mechanisms by which this occurs are just beginning to be elucidated. Within the VTA, presynaptic GLP-1R activation by the agonist exendin-4 (Ex-4) stimulates glutamatergic transmission to VTA dopamine neurons through AMPA/kainate receptors, and AMPA/kainate receptor activation is required for the intake-suppressive effects of VTA GLP-1R activation (Mietlicki-Baase et al., 2013). Whether similar glutamatergic mechanisms are involved in mediating the food intakesuppressive effects of GLP-1R action in the NAc remains unknown.

GABAergic medium spiny neurons (MSNs) constitute the major neuronal population in the NAc (Chang and Kitai, 1985). The overall activity of the NAc inversely impacts reward behavior, as increased NAc activity reduces and decreased activity enhances reward (Maldonado-Irizarry et al., 1995; Pierce et al., 1997; Roitman et al., 2005; Carlezon and Thomas, 2009). NAc MSNs receive inputs from several CNS nuclei (for review, see Shirayama and Chaki, 2006), providing many potential sources for modulation of NAc activity. Dopamine signaling from midbrain neurons in the VTA is a major source of NAc input, and dopamine release in the NAc is associated with rewarding stimuli (Bassareo et al., 2002; Brown et al., 2011; McCutcheon et al., 2012). Moreover, NAc dopamine signaling can modulate the function of MSNs (Mizuno et al., 2007; Surmeier et al., 2011), as 
well as reward-directed behavior (Hajnal and Norgren, 2001). Glutamate is another key neurotransmitter that modulates MSN signaling. The NAc receives glutamatergic inputs from numerous CNS nuclei including the amygdala, hippocampus, and thalamic and cortical structures (Floresco et al., 2001; Papp et al., 2012). Like dopamine, glutamate signaling in the NAc can modulate MSN activity to regulate reward-directed behavior (Kelley et al., 2005).

GLP-1 input to the NAc, originating from GLP-1-producing preproglucagon (PPG)-expressing NTS neurons (Dossat et al., 2011; Alhadeff et al., 2012), may modulate MSN activity to impact behavior. Although GLP-1R activation in the NAc reduces palatable food intake (Dossat et al., 2011; Alhadeff et al., 2012; Dickson et al., 2012), the location of the relevant GLP-1R populations (presynaptic or postsynaptic) is unknown. Indeed, it is possible that NAc GLP-1R activation may promote negative energy balance by modulating dopaminergic and/or glutamatergic neurotransmission onto MSNs. Here, we focus on GLP-1R signaling in the NAc core, as the anorectic effects of GLP-1R activation in the NAc are mediated predominantly by this subregion rather than the shell (Dossat et al., 2011; Alhadeff et al., 2012). Using a combination of ex vivo electrophysiological and voltammetric techniques and in vivo behavioral analyses, we test the hypothesis that GLP-1R signaling in the NAc core controls food intake by modulating MSN activity via glutamatergic and/or dopaminergic signaling.

\section{Materials and Methods}

\section{Subjects}

Adult male Sprague Dawley rats (Charles River Laboratories) were individually housed in a temperature- and humidity-controlled environment under a $12 \mathrm{~h}$ reverse light/dark cycle. Animals were housed in plastic bins for electrophysiological and voltammetric analyses and in hanging wire mesh cages for behavioral testing. Food and water were available ad libitum except where noted.

\section{Drugs}

The AMPA/kainate receptor antagonist CNQX (R\&D Systems), NMDA receptor antagonist AP-5 (Sigma), and the GLP-1R agonist Ex-4 (American Peptide), as well as cocaine and quinpirole were dissolved in artificial CSF (aCSF; Harvard Apparatus) for central injections and electrophysiological and voltammetric analyses. Doses for drugs were selected from the literature (Jones et al., 1995; Maldonado-Irizarry et al., 1995; Phillips et al., 2003; Acuna-Goycolea and van den Pol, 2004; Famous et al., 2007; Hayes et al., 2008; Schmidt et al., 2009; Alhadeff et al., 2012; Dickson et al., 2012; Mietlicki-Baase et al., 2013).

\section{Fast-scan cyclic voltammetry}

Adult male Sprague Dawley rats (375-425 g when killed) were anesthetized with ketamine/xylazine (100/10 mg/kg, i.p.), decapitated, and brains were rapidly removed. Coronal slices containing striatum (300 $\mu \mathrm{m})$, but excluding midbrain dopaminergic cell bodies, were cut on a vibrating blade microtome (Leica VT1200) in ice-cold sucrose-based aCSF containing the following (in $\mathrm{mm}$ ): 200 sucrose, $25 \mathrm{NaHCO}_{3}, 2.5$ $\mathrm{KCl}, 0.5 \mathrm{CaCl}_{2}, 3 \mathrm{MgCl}_{2}, 1 \mathrm{Na}_{2} \mathrm{HPO}_{4}, 20$ glucose, and 10 ascorbic acid. Slices were incubated for at least $1 \mathrm{~h}$ at $32-34^{\circ} \mathrm{C}$ in recovery aCSF containing the following (in mM): $\mathrm{NaCl} 120,25 \mathrm{NaHCO}_{3}, 2.5 \mathrm{KCl}, 0.5 \mathrm{CaCl}_{2}$, $3 \mathrm{MgCl}_{2}, 1 \mathrm{Na}_{2} \mathrm{HPO}_{4}, 20$ glucose, and 10 ascorbic acid. All solutions used were saturated with $95 \% \mathrm{O}_{2} / 5 \% \mathrm{CO}_{2}$. For recordings, slices were placed in a chamber and perfused with recording aCSF containing the following (in mM): $\mathrm{NaCl} 120,25 \mathrm{NaHCO}_{3}, 2.5 \mathrm{KCl}, 2.5 \mathrm{CaCl}_{2}, 1 \mathrm{MgCl}_{2}, 1$ $\mathrm{Na}_{2} \mathrm{HPO}_{4}$, and 20 glucose at room temperature. A bipolar stimulating electrode $(\sim 1 \mathrm{~mm}$ tip separation; Plastics One) was placed within the NAc core and a glass insulated carbon fiber electrode was placed between the tips. Fast-scan cyclic voltammetry has been described previously (Brown et al., 2011). Briefly, a triangular waveform $(-0.4$ to +1.3 to $-0.4 \mathrm{~V} ; 400 \mathrm{~V} / \mathrm{s}$ ) was applied to the carbon fiber electrode using custom- built hardware and software (University of Washington Electronics and Materials Engineering Shop, Seattle, WA). The waveform was initially applied at $60 \mathrm{~Hz}$ for $10 \mathrm{~min}$, to condition the electrode, and then at $10 \mathrm{~Hz}$ while all experiments were being conducted. Dopamine release was evoked by monopolar stimulation (five pulses, $25 \mathrm{~Hz}, 400 \mu \mathrm{A} / \mathrm{pulse}$ ) every $3 \mathrm{~min}$. Release of dopamine was confirmed by examining currentvoltage plots, which showed an oxidation peak at approximately $+0.6 \mathrm{~V}$ and a reduction peak at approximately $-0.2 \mathrm{~V}$ (see Fig. $1 \mathrm{~A}$, colorplot). Stimulations proceeded for $30 \mathrm{~min}$ (6 stimulations) to obtain a baseline for evoked dopamine release. Next, either aCSF $(n=4)$ administration continued or drugs [Ex-4 (1 $\mu \mathrm{M} ; n=5)$; cocaine (10 $\mu \mathrm{M} ; n=4)$; quinpirole (10 $\mu \mathrm{M} ; n=4)$; Wash In] added to aCSF were bath applied. After three stimulations, the bath source was switched back to just aCSF (Wash Out) for another four stimulations. The magnitude of evoked dopamine release was measured in $\mathrm{nA}$ and converted to nM based on postrecording calibration of each electrode using $1 \mu \mathrm{M}$ dopamine dissolved in aCSF.

\section{Electrophysiological studies}

Adult male Sprague Dawley rats (300-350 g when killed) were anesthetized by isoflurane and decapitated. Their brains were rapidly removed and coronal slices $(300 \mu \mathrm{m})$ containing the NAc were cut using a Vibratome (VT1000S; Leica Microsystems) in an ice-cold aCSF solution in which $\mathrm{NaCl}$ was replaced with an equiosmolar concentration of sucrose. aCSF contained the following (in mM): $130 \mathrm{NaCl}, 3 \mathrm{KCl}, 1.25 \mathrm{NaH}_{2} \mathrm{PO}_{4}$, $26 \mathrm{NaHCO}_{3}, 10$ glucose, $1 \mathrm{MgCl}_{2}$, and $2 \mathrm{CaCl}_{2}, \mathrm{pH}$ 7.2-7.4, when saturated with $95 \% \mathrm{O}_{2}$ and $5 \% \mathrm{CO}_{2}$. Slices were incubated in aCSF at 32 $34^{\circ} \mathrm{C}$ for $45 \mathrm{~min}$ and kept at $22-25^{\circ} \mathrm{C}$ thereafter, until transfer to the recording chamber. All solutions had osmolarity between 305 and 315 mOsm. Slices were viewed under an upright microscope (Eclipse FN1; Nikon Instruments) with infrared differential interference contrast optics and a $40 \times$ water-immersion objective. For recordings, the chamber was continuously perfused at a rate of $1-2 \mathrm{ml} / \mathrm{min}$ with oxygenated aCSF heated to $32 \pm 1^{\circ} \mathrm{C}$ using an automated temperature controller (Warner Instruments). Recording pipettes were pulled from borosilicate glass capillaries (World Precision Instruments) to a resistance of 4-7 M $\Omega$ when filled with the intracellular solution. The intracellular solution contained the following (in $\mathrm{mM}$ ): 145 potassium gluconate, $2 \mathrm{MgCl}_{2}, 2.5 \mathrm{KCl}$, $2.5 \mathrm{NaCl}, 0.1$ BAPTA, 10 HEPES, $2 \mathrm{Mg}$-ATP, 0.5 GTP-Tris, and 1 QX314 , pH 7.2-7.3, with KOH, osmolarity $280-290 \mathrm{mOsm}$. The presence of magnesium in the solution and hyperpolarized holding current $\left(V_{\mathrm{h}}=\right.$ $-70 \mathrm{mV}$ ) prevented activation of NMDA-mediated currents, allowing us to isolate AMPA/kainate-mediated effects.

NAc core MSNs were identified by their morphology and low resting membrane potential ( -70 to $-85 \mathrm{mV})$. Miniature EPSC (mEPSC) recordings were conducted in the presence of tetrodotoxin $(1 \mu \mathrm{M})$ in whole-cell voltage-clamp mode $\left(V_{\mathrm{h}}=-70 \mathrm{mV}\right)$ using a MultiClamp700B amplifier (Molecular Devices); the inclusion of TTX blocks the voltagegated sodium channels and prevents the generation of action potentials in mEPSC experiments. QX-314 was omitted from the intracellular solution in experiments evaluating action potential firing. For paired-pulse ratio (PPR) experiments, evoked responses with an interstimulus interval of $100 \mathrm{~ms}$ were triggered by $100 \mu$ s constant-current pulses generated by an A310 Accupulser (World Precision Instruments) and delivered at $0.2 \mathrm{~Hz}$ via a bipolar tungsten stimulation electrode positioned within 100 $\mu \mathrm{m}$ of the recorded cell. Ex-4 $(1 \mu \mathrm{M})$ was applied via the Y-tube perfusion system modified for optimal solution exchange in brain slices. Neurons from a total of four animals were analyzed. All Ex-4 data were collected after a minimum of $4 \mathrm{~min}$ of Ex- 4 exposure. Currents were low-pass filtered at $2 \mathrm{kHz}$ and digitized at $20 \mathrm{kHz}$ using a Digidata 1440A acquisition board (Molecular Devices) and pClamp10 software (Molecular Devices). Access resistance (10-30 M $\Omega$ ) was monitored during recordings by injection of $10 \mathrm{mV}$ hyperpolarizing pulses; data were discarded if access resistance changed $>25 \%$ over the course of data collection.

\section{Behavioral testing}

Surgery. Rats were anesthetized with an intramuscular injection containing ketamine $(90 \mathrm{mg} / \mathrm{kg})$, xylazine $(2.7 \mathrm{mg} / \mathrm{kg})$, and acepromazine $(0.64$ $\mathrm{mg} / \mathrm{kg}$ ) and subsequently placed into a stereotaxic apparatus. Each rat was stereotaxically implanted with a unilateral guide cannula (26 gauge; 
A

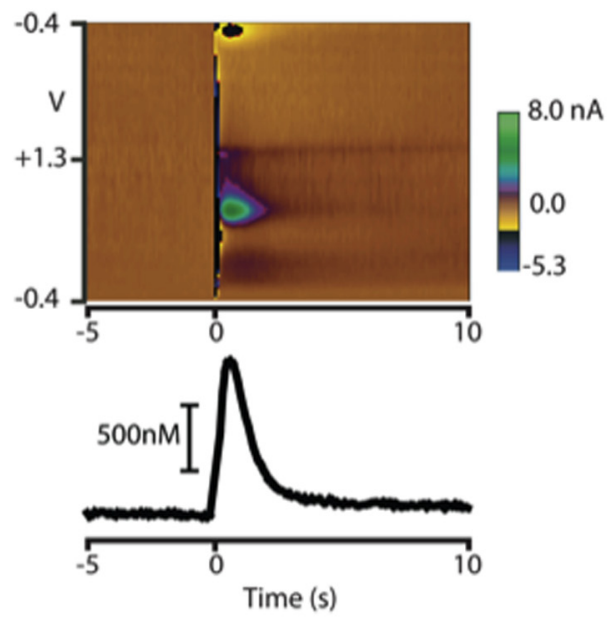

B

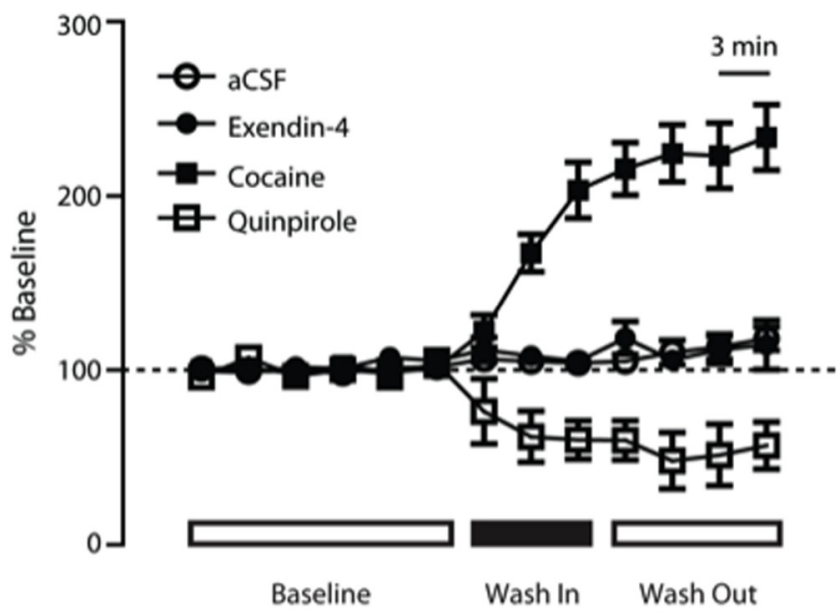

Figure 1. Ex-4 does not act on NAc core dopaminergic terminals to modulate dopamine release. $A$, A single stimulation example of evoked release in the NAc core during Baseline. Top, Colorplot depicting current (color) as a function of electrode potential ( $y$-axis) in the 5 s before and $10 \mathrm{~s}$ after ( $x$-axis) electrical stimulation of the slice (time $=0$; vertical color stripe). Dopamine is identified by its oxidation (approximately $+0.6 \mathrm{~V}$; green) and reduction (approximately $-0.2 \mathrm{~V}$; blue) features. Bottom, Dopamine concentration over time extracted from the data above (stimulation artifact removed). $\boldsymbol{B}$, Average peak dopamine concentration over time during Baseline, Wash In, and Wash Out of different drugs expressed as percentage change relative to average Baseline dopamine concentration. Symbols and error bars indicate the mean $\pm 1 \mathrm{SEM}$.

Plastics One) positioned $2 \mathrm{~mm}$ above the NAc core (coordinates: $2.5 \mathrm{~mm}$ anterior to bregma, $1.4 \mathrm{~mm}$ left of midline, $4.5 \mathrm{~mm}$ ventral to skull; injector aimed $6.5 \mathrm{~mm}$ ventral to skull). Cannulae were affixed to the skull with dental acrylic and jeweler's screws. Analgesia was provided for all surgeries (meloxicam, $2 \mathrm{mg} / \mathrm{kg}$ ). NAc core cannula placements were verified histologically postmortem with injection of pontamine sky blue ink $(100 \mathrm{nl})$. A representative image of NAc core cannula placement is shown in Figure $4 C$.

Behavioral experimentation. Nonobese rats $(n=8 ; 351.9 \pm 15.8 \mathrm{~g}$ at the beginning of experimental testing) were maintained on high-fat diet (HFD; 60\% kcal from fat; Research Diets) for 1 week before testing, as our previous findings indicate that NAc core GLP-1R activation preferentially reduces intake of HFD compared with chow (Alhadeff et al., 2012; Mietlicki-Baase et al., 2013). Shortly before the onset of the dark phase, nondeprived rats received unilateral intra-NAc core injections of the AMPA/kainate receptor antagonist CNQX $(0.3 \mu \mathrm{g}$; dose selection from Schmidt et al., 2009 and Mietlicki-Baase et al., 2013) or its vehicle $(100 \mathrm{nl}$ aCSF) followed by a second intra-NAc core injection of the GLP-1R agonist Ex-4 (0.05 $\mu \mathrm{g}$; dose selection from Alhadeff et al., 2012 and Mietlicki-Baase et al., 2013) or its vehicle (100 nl aCSF). At dark onset, rats were given access to preweighed HFD; cumulative food intake was measured to the nearest $0.1 \mathrm{~g}$, accounting for spillage, at 1,3,6, and $24 \mathrm{~h}$. Body weight change over the $24 \mathrm{~h}$ test period was also measured. Rats received all four possible drug combinations in a counterbalanced design, with treatments separated by at least $72 \mathrm{~h}$. A separate group of nonobese, ad libitum HFD-maintained rats $(n=6 ; 313.3 \pm 21.3 \mathrm{~g}$ at the beginning of experimental testing) received unilateral intra-NAc core injections of the NMDA receptor antagonist AP-5 ( $1 \mu \mathrm{g}$; dose chosen from Maldonado-Irizarry et al., 1995) or its vehicle (100 $\mathrm{nl} \mathrm{aCSF})$ followed by a second intra-NAc core injection of Ex-4 $(0.05 \mu \mathrm{g})$ or its vehicle (100 $\mathrm{nl}$ aCSF) in a within-subjects, counterbalanced design. Similar to the CNQX experiment, HFD intake (1, 3, 6, and $24 \mathrm{~h})$ and $24 \mathrm{~h}$ body weight change were analyzed.

\section{Data analyses and statistics}

The $\alpha$ level for all tests was set at $p<0.05$. For voltammetric analyses, dopamine concentration was expressed as a percentage of average baseline for each treatment condition (aCSF, Ex-4, cocaine, and quinpirole) and statistically compared using a two-way ANOVA with Bonferroni post hoc comparisons, at each time point, against aCSF treatment. For electrophysiological studies, all analyses were completed using Clampfit 10 (Molecular Devices). The time constant of decay was based on a monoexponential fit to the decay phase of an average mEPSC trace computed from a minimum of 60 individual mEPSCs. Mean mEPSC frequencies were analyzed from $20 \mathrm{~s}$ trace segments. PPRs were calculated by averaging 5-10 responses and dividing the peak amplitude of the second evoked EPSC by the peak amplitude of the first evoked EPSC. Statistical comparisons were done using two-tailed paired Student's $t$ tests. For behavioral tests, statistical analyses were conducted using Statistica (StatSoft). Binned food intake and body weight data were analyzed using separate mixed-design ANOVAs to account for the within-subjects experimental design while assessing between-subjects effects of drug treatments. Statistically significant effects were probed using Student-Newman-Keuls post hoc analyses.

\section{Results}

\section{GLP-1R activation in the NAc core does not affect}

\section{dopamine release}

The NAc core receives robust dopaminergic input from the VTA (Fallon and Moore, 1978; Phelix and Broderick, 1995), and dopamine signaling within the core mediates aspects of food intake (Bassareo and Di Chiara, 1999; Bassareo et al., 2002; Roitman et al., 2004). Here, we used fast-scan cyclic voltammetry to investigate whether GLP-1R activation directly in the NAc core can affect MSN activity, in part, by modulating dopamine release from dopamine terminals. As expected, electrical stimulation reliably evoked a brief increase in dopamine release in every slice (Fig. 1A). Average baseline evoked dopamine did not differ across treatment conditions $\left(F_{(3,13)}=0.72\right.$; n.s. $)$. Bath application of Ex-4 was compared with positive (cocaine, quinpirole) and negative (aCSF) controls. As seen in Figure $1 B$ and supported by a significant interaction $\left(F_{(36,156)}=20.13 ; p<0.0001\right)$, treatments differentially affected the magnitude of evoked dopamine release. Bonferroni post hoc comparisons against aCSF revealed that, consistent with prior work (Jones et al., 1995), the dopamine transporter blocker cocaine significantly increased the magnitude of evoked dopamine release at $6 \mathrm{~min}$ after the introduction of cocaine (maximum increase at 15 min post introduction; $224.5 \pm$ $16 \%$ of Baseline, mean \pm 1 SEM) through the end of the recording session. Also consistent with prior work (Phillips et al., 2003), the dopamine D2 receptor agonist quinpirole significantly suppressed the magnitude of evoked dopamine release at $6 \mathrm{~min}$ after the introduction of quinpirole (maximum decrease at $15 \mathrm{~min}$ 

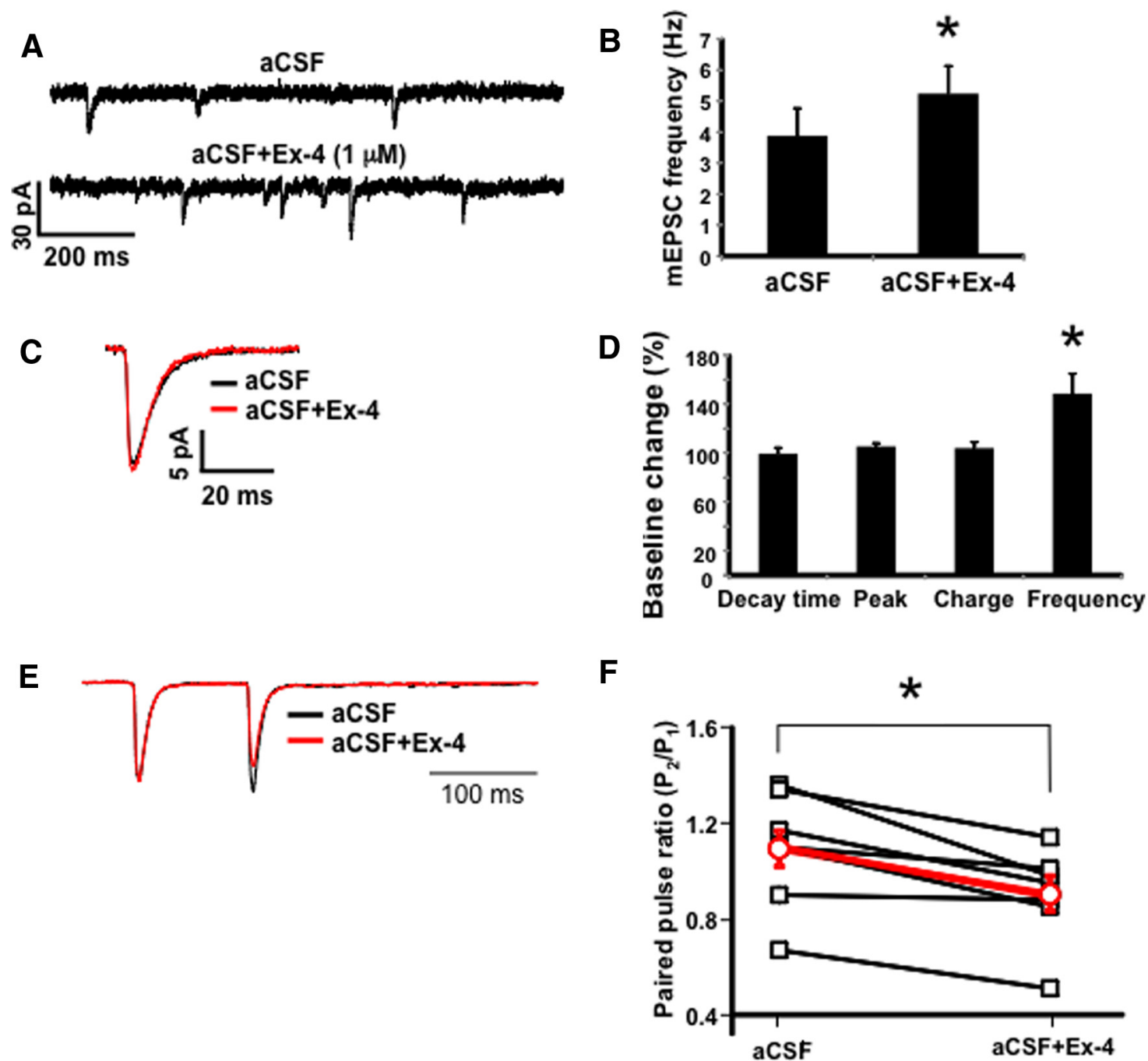

Figure 2. A, Representative mEPSC traces from a NAc core MSN before and during Ex-4 bath application. $B$, Ex-4 application increases the frequency of $m E P S C s$. The effect of Ex-4 on mEPSC averages is shown in $\boldsymbol{C}$ and is expressed as a percentage difference from aCSF baseline before Ex-4 application in $\boldsymbol{D}$. Ex-4 also reduces PPR in NAc core MSNs (E); the results from PPR analyses are quantified in $\boldsymbol{F}$ (black lines indicate individual neuron responses before and during Ex-4 application, with the mean indicated by the red line); ${ }^{*} p<0.05$. Quantified data are shown as mean \pm SEM.

post introduction; $48.2 \pm 16 \%$ of Baseline, mean \pm 1 SEM) through the end of the recording session. While these positive controls had a profound effect on evoked dopamine release, bath administration of Ex-4 was not different from aCSF at any time point. These data indicate that a change in dopamine release likely does not contribute to a change in MSN activity or suppression in food intake by NAc core GLP-1R activation.

Presynaptic GLP-1Rs in the NAc core modulate MSN activity via a glutamatergic, AMPA/kainate-mediated mechanism Glutamatergic input in the NAc regulates the neuronal activity of MSNs (Stefani et al., 1998; Britt et al., 2012). Furthermore, NAc glutamatergic signaling, particularly via AMPA/kainate receptors, is required for the normal control of food intake (Maldonado-Irizarry et al., 1995). Within the NAc, GLP-1Rs in the core subregion are physiologically relevant for energy balance regulation (Alhadeff et al., 2012). Given these previous findings, and having determined that NAc core GLP-1R activation does not alter dopamine release evoked from terminals, we hypothesized that NAc core GLP-1R activation increases the strength of glutamatergic, AMPA-kainate receptor-mediated transmission in MSNs.
Using whole-cell patch-clamp electrophysiology, we recorded pharmacologically isolated, AMPA/kainate-mediated mEPSCs from NAc core MSNs before and during bath application of Ex-4 $(1 \mu \mathrm{M})$. The frequency of MSN mEPSCs increased during Ex-4 application (Figure $2 A, B, D ; t_{(6)}=15.60, p<0.0001$ ), suggesting a presynaptic effect of GLP-1R activation. In contrast, mEPSC kinetics and amplitude were unaffected by Ex-4 (Figure 2C,D; $p>0.05)$, arguing against postsynaptic GLP-1R effects on MSNs. To confirm the presynaptic GLP-1R effect, we analyzed the PPR of MSNs before and after Ex-4 bath application. Consistent with the mEPSC data, Ex-4 decreased the PPR of evoked EPSCs (Figure $2 E, F ; t_{(6)}=4.31, p<0.01$ ), providing further support that GLP-1Rs exert their effects presynaptically, presumably by increasing the probability of glutamate release.

To directly test the possible contribution of postsynaptic GLP-1R to MSN activity, we evaluated the effect of Ex-4 on action potential firing in MSNs. Ex-4 treatment mildly depressed the frequency of action potential firing in MSNs (Fig. 3); this reduction was associated with a small but significant decrease in resting membrane potential $(\mathrm{aCSF}=-75.3 \pm 1.3 \mathrm{mV}, \mathrm{aCSF}+\mathrm{Ex}-4=$ $-78.6 \pm 1.1 \mathrm{mV} ; p<0.02)$. Together, these data indicate a small contribution of postsynaptic GLP-1R activation to MSN activity. 
A

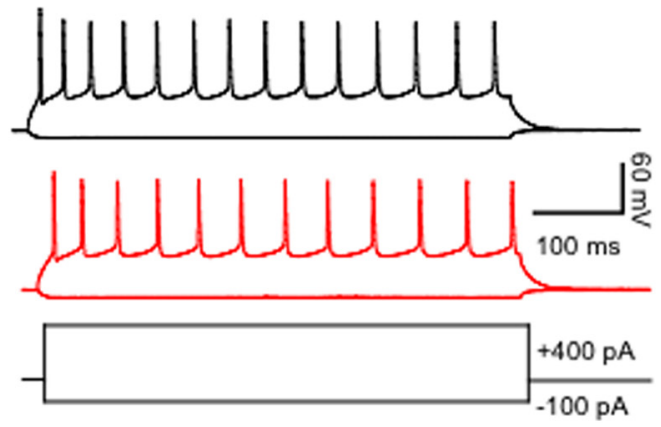

B

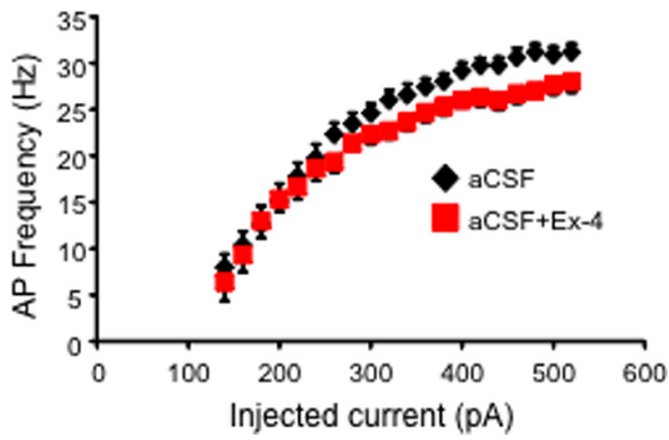

Figure 3. A,Current-clamp traces from a representative MSN illustrate a small reduction in evoked action potential firing during Ex-4 application (black trace, aCSF; red trace, Ex-4). B, A summary of the action potential frequency versus injected current $(f-l)$ relationship in NAc core MSNs before and during Ex-4 application. Quantified data are shown as mean \pm SEM.

These postsynaptic effects of GLP-1R activation are likely independent of AMPA/kainate receptor signaling, however, given that the mEPSC charge, decay time, and amplitude were not altered by Ex-4 (Fig. 2D). Collectively, the data indicate that GLP-1R activation in the NAc core activates MSNs predominantly by a presynaptic, AMPA/kainate-mediated glutamatergic mechanism, with slight postsynaptic effects.

Blockade of AMPA/kainate receptors, but not NMDA receptors, in the NAc core attenuates the food intake- and body weight-suppressive effects of intra-NAc core GLP-1R activation

Given the findings that GLP-1R activation in the NAc core increases AMPA/kainate-mediated glutamatergic signaling in the core, we tested the hypothesis that the increased AMPA/kainate signaling is required for the suppression of food intake and body weight gain produced by NAc core GLP-1R activation. Consistent with previous studies (Alhadeff et al., 2012), delivery of the GLP-1R agonist Ex-4 $(0.05 \mu \mathrm{g})$ into the NAc core reduced HFD intake at 3,6 , and $24 \mathrm{~h}$ post injection (Fig. $4 A$; main effect of Ex-4 from 3 to $24 \mathrm{~h}$, all ANOVAs $\left.F_{(1,7)} \geq 5.88, p<0.05\right)$. Intra-NAc core pretreatment with the AMPA/kainate receptor antagonist CNQX $(0.3 \mu \mathrm{g})$ attenuated this Ex-4-induced suppression of feeding at 6 and $24 \mathrm{~h}$ (Fig. $4 A$; main effects of CNQX and Ex-4 at 6 and $24 \mathrm{~h}$, all ANOVAs $F_{(1,7)} \geq 5.88, p<0.05$; interaction between CNQX and Ex-4 at $24 \mathrm{~h}, F_{(1,7)}=7.64, p<0.03$; planned comparisons between aCSF/Ex-4 and CNQX/Ex-4 at 6 and $24 \mathrm{~h}$, $p<0.03)$. Twenty-four hour body weight gain was also decreased by intra-NAc core Ex-4 (Fig. 4B, interaction of CNQX and Ex-4, $F_{(1,7)}=8.06, p<0.03$; planned comparison between aCSF/aCSF and $\mathrm{aCSF} / \mathrm{Ex}-4, p=0.03$ ), whereas no significant change in body weight was observed in rats given the combination of CNQX and Ex-4 (Fig. 4B; planned comparison between aCSF/aCSF and CNQX/Ex-4, $p=0.18$ ).

To assess a possible contribution of glutamatergic NMDA receptors in mediating the intake suppressive effects of NAc core GLP-1R activation by Ex-4, rats were given intracore injection of the NMDA receptor antagonist AP-5 $(1 \mu \mathrm{g})$ in conjunction with intracore injection of Ex-4 $(0.05 \mu \mathrm{g})$, and subsequent HFD intake and body weight gain were measured. As expected, Ex-4 reliably reduced food intake (Fig. 5A; main effects of Ex-4 at 3, 6, and $24 \mathrm{~h}$, all ANOVAs $F_{(1,5)} \geq 13.14, p<0.02$ ) and body weight gain (Fig. $5 B$; main effect of Ex-4, $\left.F_{(1,5)}=7.45, p<0.05\right)$. However, unlike CNQX, intracore administration of AP-5 had no effect on the ability of NAc core Ex-4 to suppress food intake and body weight gain over the $24 \mathrm{~h}$ testing period (for all significant main effects ANOVAs, planned comparisons between aCSF/Ex-4 and AP-5/

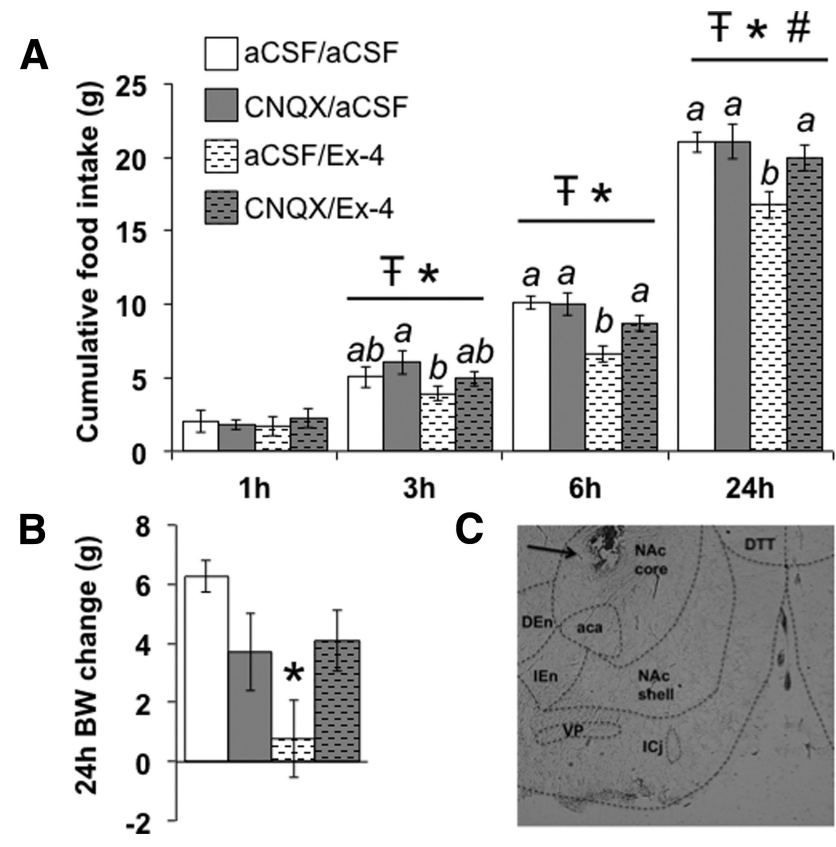

Figure 4. AMPA/kainate receptors are required for the food intake- and body weightsuppressive effects of NAc core GLP-1R activation. $A$, Intra-NAc core injection of the GLP-1R agonist Ex-4 (0.05 $\mu \mathrm{g}$; vehicle, $100 \mathrm{nl}$ aCSF) suppresses intake of a palatable HFD beginning at $3 \mathrm{~h}$ post injection. This effect is attenuated by intracore pretreatment with the AMPA/kainate receptor antagonist CNQX ( $0.3 \mu$ g; vehicle, $100 \mathrm{nl}$ aCSF) at 6 and $24 \mathrm{~h}$. T, main effect of CNQX; ${ }^{*}$, main effect of Ex-4; \#, interaction between CNQX and Ex-4 (all $p<0.05$ ); within a time bin, bars with different letters are significantly different $(p<0.05)$. B, Body weight gain over the $24 \mathrm{~h}$ test period was significantly decreased by NAc core Ex-4, but not by the combination of CNQX and Ex-4. ${ }^{*} p<0.05$, significantly different from aCSF/aCSF. All quantified data are shown as mean \pm SEM. The key in $\boldsymbol{A}$ also applies to $\boldsymbol{B}$. C, Representative histological image depicting verification of proper NAc core cannula placement with $100 \mathrm{nl}$ pontamine sky blue ink. DTT, Dorsal tenia tecta; Den, dorsal endopiriform nucleus; aca, anterior part of the anterior commissure; IEn, intermediate endopiriform nucleus; VP, ventral pallidum; ICj, islands of Calleja.

Ex-4 $p>0.05)$. Together, these findings confirm that AMPA/ kainate-mediated, but not NMDA-mediated, glutamatergic signaling is required for the ability of intra-NAc core GLP-1R activation to promote negative energy balance.

\section{Discussion}

The current data support the hypothesis that GLP-1R activation in the NAc core promotes negative energy balance in part by a glutamatergic, AMPA/kainate receptor-mediated mechanism. Electrophysiological studies establish that presynaptic GLP-1R stimulation in the NAc core increases the probability of gluta- 
A

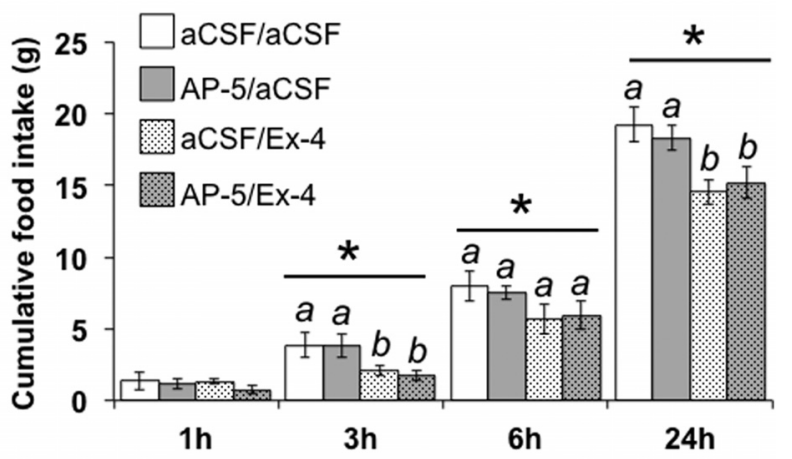

B

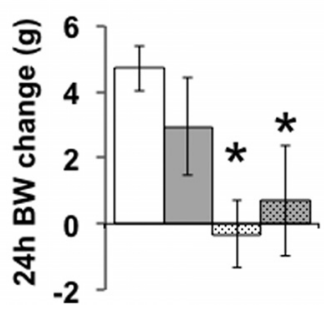

Figure 5. NMDA receptors are not required for the energy balance effects of NAc core GLP-1R activation. $\boldsymbol{A}$, Intra-NAc core injection of Ex-4 ( $0.05 \mu$ g; vehicle, $100 \mathrm{nl}$ aCSF) reduces palatable HFD consumption beginning at $3 \mathrm{~h}$ post injection, but intracore NMDA receptor blockade using AP-5 (1 $\mu$ g; vehicle, $100 \mathrm{nl}$ aCSF) does not alter the ability of NAc core GLP-1R activation to suppress intake. ${ }^{*} p<0.05$, main effect of Ex-4; within a time bin, bars with different letters are significantly different. $\boldsymbol{B}$, Body weight gain over the $24 \mathrm{~h}$ test period was significantly decreased by NAc core Ex-4; AP-5 did not alter this effect. ${ }^{*} p<0.05$, main effect of Ex-4. All quantified data are shown as mean \pm SEM. The key in $\boldsymbol{A}$ also applies to $\boldsymbol{B}$.

mate release within this site, subsequently enhancing the mEPSC frequency at postsynaptic AMPA/kainate receptors in GABAergic MSNs. Behavioral studies confirmed the requirement of AMPA/kainate receptor activation to mediate the suppression of food intake by NAc core GLP-1R activation, as intra-NAc core administration of an AMPA/kainate receptor antagonist, attenuated the suppression of food intake and body weight gain produced by intra-NAc core Ex-4. Importantly, glutamatergic NMDA receptor blockade with intracore injection of AP-5 had no impact on the energy balance effects of NAc core GLP-1R activation.

The NAc core receives glutamatergic input from a variety of nuclei including the prefrontal cortex (PFC), the amygdala, and the hippocampus, among others (for review, see Kelley et al., 2005). Our data indicate that NAc core presynaptic GLP-1Rs on intracore glutamate terminals modulate glutamatergic AMPA/ kainate signaling to MSNs to reduce feeding. Together with the previous finding that GLP-1Rs in the NAc core are physiologically relevant for the control of feeding (Dossat et al., 2011; Alhadeff et al., 2012), this suggests that the NAc core may respond to endogenous GLP-1 to promote negative energy balance through presynaptic modulation of glutamate signaling. GLP-1producing PPG NTS neurons are activated by an array of energy status signals including gastric distension (Vrang et al., 2003; Hayes et al., 2009), inflammation/stress signaling (Gaykema et al., 2009; Zhang et al., 2009), and intestinally derived satiation signals like cholecystokinin (Hisadome et al., 2011). As NTS PPG neurons project monosynaptically to the NAc core (Dossat et al., 2011; Alhadeff et al., 2012), this indicates a potential physiological pathway by which GLP-1 release in the NAc core is induced and may contribute to feeding behavior. Indeed, the presynaptic, glutamatergic mechanism of GLP-1R action in the NAc in the present studies is also observed in other nuclei, including the VTA (Mietlicki-Baase et al., 2013) and the hypothalamus (Acuna-Goycolea and van den Pol, 2004), hinting at the possibility that this may be a general mechanism by which GLP-1R activation in forebrain nuclei modulates neuronal activity to control feeding.

Although the current data indicate the importance of presynaptic GLP-1R modulation of intracore glutamate signaling for the control of feeding, they do not identify the source of these glutamatergic inputs. Given the recent discovery that peripheral GLP-1 analogs can decrease the rewarding properties of drugs of abuse (Egecioglu et al., 2013; Graham et al., 2013; Shirazi et al., 2013), the glutamatergic PFC-core projection may be of particular interest, as this pathway has been implicated in drug-seeking behavior (McFarland et al., 2003; LaLumiere and Kalivas, 2008). NAc GLP-1 signaling also decreases the rewarding value of palatable food, demonstrated by the finding that motivation to work for sucrose pellets is reduced by intra-NAc Ex-4 (Dickson et al., 2012). These previous findings, together with our current data, highlight the intriguing possibility that intra-NAc, presynaptic GLP-1R may modulate incoming PFC glutamatergic input to reduce the rewarding value of various types of stimuli (food, drug). Nevertheless, several CNS nuclei send glutamatergic projections to the NAc core (Kelley et al., 2005), and the possibility that presynaptic GLP-1R in the core might regulate glutamatergic neurotransmission originating from additional or alternate (non-PFC) nuclei should not be discounted. Such hypotheses require further testing.

Current ex vivo analyses focused on examining alterations in glutamatergic AMPA/kainate receptor signaling, rather than NMDA-mediated effects, for several reasons. First, blockade of NAc AMPA/kainate receptors increases food intake, whereas NAc NMDA receptor antagonism has no effect on feeding (Maldonado-Irizarry et al., 1995). In addition, the anorectic effects of GLP-1R activation in another MRS site, the VTA, are dependent on signaling by AMPA/kainate but not NMDA receptors (Mietlicki-Baase et al., 2013). Together, these previous findings suggest a role for non-NMDA receptors in MRS GLP$1 \mathrm{R}$-mediated control of feeding. Indeed, our behavioral data support the hypothesis that AMPA/kainate receptor signaling is necessary for the food intake-suppressive effects of NAc core GLP-1R activation, as intracore AMPA/kainate receptor blockade, but not NMDA receptor blockade, attenuates the energy balance effects of NAc core GLP-1R activation. However, these data do not rule out the possibility that nonglutamatergic signaling may factor into the ability of intra-NAc core Ex-4 to reduce food intake and body weight. In fact, the finding that intra-NAc core CNQX attenuated, but did not completely block, the effects of Ex-4 in this subnucleus suggests that alternate mechanisms may also mediate a percentage of the intake-suppressive effects of NAc core GLP-1R activation. As GLP-1R activation did produce a small but significant reduction in resting membrane potential in the MSN, it is possible that direct postsynaptic effects also marginally contribute to the intake-suppressive effects of intraNAc Ex-4 administration. It is also worth considering the notion that the minor postsynaptic GLP-1R effects observed from Ex-4 may induce release of a diffusible retrograde transmitter to activate presynaptic glutamatergic neurons. The regulation of feeding behavior by retrograde signals, such as the endocannabinoids (Perez-Morales et al., 2012), is only beginning to be understood; Ex-4-mediated release of an unidentified retrograde signal is an explanation that would integrate the predominantly presynaptic GLP-1R effects observed here with the small postsynaptic effects. 
Another extremely remote possibility is that NAc Ex-4 activates some yet unidentified alternative receptor other than the GLP1R. However, given that Ex-4 is well established as a GLP-1R agonist, this seems unlikely.

In the VTA, GLP-1R activation engages a glutamatergic, AMPA/kainate-mediated mechanism to increase the EPSC frequency in VTA dopamine neurons (Mietlicki-Baase et al., 2013). In addition, intra-VTA Ex-4 increases tyrosine hydroxylase within the VTA (Mietlicki-Baase et al., 2013), suggesting enhanced production of dopamine. Although the VTA sends robust dopaminergic projections to the NAc core (Fallon and Moore, 1978; Phelix and Broderick, 1995), our results indicate that GLP-1R signaling within the NAc core by Ex-4 does not alter phasic dopamine release, further suggesting that GLP-1Rs are probably not located on presynaptic dopaminergic terminals within the core. However, the possibility that activation of intraVTA GLP-1R may alter dopamine release in the NAc core has not yet been tested. An additional consideration is that although GLP-1-producing neurons in the NTS project monosynaptically to both the NAc core (Dossat et al., 2011; Alhadeff et al., 2012) and to the VTA (Alhadeff et al., 2012), it is unknown whether the projections to each site are simultaneously activated. It may be that separate subpopulations of NTS GLP-1-producing neurons are activated under different conditions and perhaps specifically stimulate GLP-1Rs in one nucleus versus another to regulate food intake. Alternatively, multiple MRS GLP-1R-expressing nuclei may be concurrently activated by NTS-derived GLP-1 and thus act cooperatively to promote negative energy balance. Such hypotheses require further examination.

Given that GLP-1R agonists are widely used in the treatment of type 2 diabetes mellitus (Davidson et al., 2005; Parks and Rosebraugh, 2010) and have physiologically relevant effects through direct action in the CNS (Kanoski et al., 2011, 2012), there is an urgent need to understand more fully the downstream effects of GLP-1R activation in distributed CNS sites. The current data provide evidence that intra-NAc core GLP-1R activation suppresses food intake and body weight gain at least in part via glutamatergic AMPA/kainate receptor signaling, but does not alter NAc core dopamine release. These findings demonstrate a novel mechanism by which intracore GLP-1R activation suppresses palatable food intake. Along with previous data describing a similar effect of VTA GLP-1R activation to enhance glutamatergic neurotransmission, the present results support the idea that GLP-1R signaling in the MRS engages glutamatergic neurotransmission to promote negative energy balance.

\section{References}

Acuna-Goycolea C, van den Pol A (2004) Glucagon-like peptide 1 excites hypocretin/orexin neurons by direct and indirect mechanisms: implications for viscera-mediated arousal. J Neurosci 24:8141-8152. CrossRef Medline

Alhadeff AL, Rupprecht LE, Hayes MR (2012) GLP-1 neurons in the nucleus of the solitary tract project directly to the ventral tegmental area and nucleus accumbens to control for food intake. Endocrinology 153:647658. CrossRef Medline

Bassareo V, Di Chiara G (1999) Differential responsiveness of dopamine transmission to food-stimuli in nucleus accumbens shell/core compartments. Neuroscience 89:637-641. CrossRef Medline

Bassareo V, De Luca MA, Di Chiara G (2002) Differential expression of motivational stimulus properties by dopamine in nucleus accumbens shell versus core and prefrontal cortex. J Neurosci 22:4709-4719. Medline

Britt JP, Benaliouad F, McDevitt RA, Stuber GD, Wise RA, Bonci A (2012) Synaptic and behavioral profile of multiple glutamatergic inputs to the nucleus accumbens. Neuron 76:790-803. CrossRef Medline
Brown HD, McCutcheon JE, Cone JJ, Ragozzino ME, Roitman MF (2011) Primary food reward and reward-predictive stimuli evoke different patterns of phasic dopamine signaling throughout the striatum. Eur J Neurosci 34:1997-2006. CrossRef Medline

Carlezon WA Jr, Thomas MJ (2009) Biological substrates of reward and aversion: a nucleus accumbens activity hypothesis. Neuropharmacology 56 [Suppl 1]:122-132. CrossRef Medline

Chang HT, Kitai ST (1985) Projection neurons of the nucleus accumbens: an intracellular labeling study. Brain Res 347:112-116. CrossRef Medline

Davidson MB, Bate G, Kirkpatrick P (2005) Exenatide. Nat Rev Drug Discov 4:713-714. CrossRef Medline

Dickson SL, Shirazi RH, Hansson C, Bergquist F, Nissbrandt H, Skibicka KP (2012) The glucagon-like peptide 1 (GLP-1) analogue, exendin-4, decreases the rewarding value of food: a new role for mesolimbic GLP-1 receptors. J Neurosci 32:4812-4820. CrossRef Medline

Dossat AM, Lilly N, Kay K, Williams DL (2011) Glucagon-like peptide 1 receptors in nucleus accumbens affect food intake. J Neurosci 31:1445314457. CrossRef Medline

Egecioglu E, Engel JA, Jerlhag E (2013) The glucagon-like peptide 1 analogue, exendin-4, attenuates the rewarding properties of psychostimulant drugs in mice. PLoS One 8:e69010. CrossRef Medline

Fallon JH, Moore RY (1978) Catecholamine innervation of the basal forebrain. IV. Topography of the dopamine projection to the basal forebrain and neostriatum. J Comp Neurol 180:545-580. CrossRef Medline

Famous KR, Schmidt HD, Pierce RC (2007) When administered into the nucleus accumbens core or shell, the NMDA receptor antagonist AP-5 reinstates cocaine-seeking behavior in the rat. Neurosci Lett 420:169-173. CrossRef Medline

Floresco SB, Todd CL, Grace AA (2001) Glutamatergic afferents from the hippocampus to the nucleus accumbens regulate activity of ventral tegmental area dopamine neurons. J Neurosci 21:4915-4922. Medline

Gaykema RP, Daniels TE, Shapiro NJ, Thacker GC, Park SM, Goehler LE (2009) Immune challenge and satiety-related activation of both distinct and overlapping neuronal populations in the brainstem indicate parallel pathways for viscerosensory signaling. Brain Res 1294:61-79. CrossRef Medline

Graham DL, Erreger K, Galli A, Stanwood GD (2013) GLP-1 analog attenuates cocaine reward. Mol Psychiatry 18:961-962. CrossRef Medline

Hajnal A, Norgren R (2001) Accumbens dopamine mechanisms in sucrose intake. Brain Res 904:76-84. CrossRef Medline

Hayes MR, Skibicka KP, Grill HJ (2008) Caudal brainstem processing is sufficient for behavioral, sympathetic, and parasympathetic responses driven by peripheral and hindbrain glucagon-like-peptide-1 receptor stimulation. Endocrinology 149:4059-4068. CrossRef Medline

Hayes MR, Bradley L, Grill HJ (2009) Endogenous hindbrain glucagon-like peptide-1 receptor activation contributes to the control of food intake by mediating gastric satiation signaling. Endocrinology 150:2654-2659. CrossRef Medline

Hisadome K, Reimann F, Gribble FM, Trapp S (2011) CCK stimulation of GLP-1 neurons involves alphal-adrenoceptor-mediated increase in glutamatergic synaptic inputs. Diabetes 60:2701-2709. CrossRef Medline

Holst JJ (2007) The physiology of glucagon-like peptide 1. Physiol Rev 87: 1409-1439. CrossRef Medline

Jones SR, Garris PA, Wightman RM (1995) Different effects of cocaine and nomifensine on dopamine uptake in the caudate-putamen and nucleus accumbens. J Pharmacol Exp Ther 274:396-403. Medline

Kanoski SE, Fortin SM, Arnold M, Grill HJ, Hayes MR (2011) Peripheral and central GLP-1 receptor populations mediate the anorectic effects of peripherally administered GLP-1 receptor agonists, liraglutide and exendin-4. Endocrinology 152:3103-3112. CrossRef Medline

Kanoski SE, Rupprecht LE, Fortin SM, De Jonghe BC, Hayes MR (2012) The role of nausea in food intake and body weight suppression by peripheral GLP-1 receptor agonists, exendin-4 and liraglutide. Neuropharmacology 62:1916-1927. CrossRef Medline

Kelley AE, Baldo BA, Pratt WE, Will MJ (2005) Corticostriatal-hypothalamic circuitry and food motivation: integration of energy, action and reward. Physiol Behav 86:773-795. CrossRef Medline

LaLumiere RT, Kalivas PW (2008) Glutamate release in the nucleus accumbens core is necessary for heroin seeking. J Neurosci 28:3170-3177. CrossRef Medline

Maldonado-Irizarry CS, Swanson CJ, Kelley AE (1995) Glutamate receptors 
in the nucleus accumbens shell control feeding behavior via the lateral hypothalamus. J Neurosci 15:6779-6788. Medline

McCutcheon JE, Beeler JA, Roitman MF (2012) Sucrose-predictive cues evoke greater phasic dopamine release than saccharin-predictive cues. Synapse 66:346-351. CrossRef Medline

McFarland K, Lapish CC, Kalivas PW (2003) Prefrontal glutamate release into the core of the nucleus accumbens mediates cocaine-induced reinstatement of drug-seeking behavior. J Neurosci 23:3531-3537. Medline

Mietlicki-Baase EG, Ortinski PI, Rupprecht LE, Olivos DR, Alhadeff AL, Pierce RC, Hayes MR (2013) The food intake-suppressive effects of glucagon-like peptide-1 receptor signaling in the ventral tegmental area are mediated by AMPA/kainate receptors. Am J Physiol Endocrinol Metab 305:E1367-E1374. CrossRef Medline

Mizuno T, Schmauss C, Rayport S (2007) Distinct roles of presynaptic dopamine receptors in the differential modulation of the intrinsic synapses of medium-spiny neurons in the nucleus accumbens. BMC Neurosci 8:8. CrossRef Medline

Papp E, Borhegyi Z, Tomioka R, Rockland KS, Mody I, Freund TF (2012) Glutamatergic input from specific sources influences the nucleus accumbens-ventral pallidum information flow. Brain Struct Funct 217: 37-48. CrossRef Medline

Parks M, Rosebraugh C (2010) Weighing risks and benefits of liraglutidethe FDA's review of a new antidiabetic therapy. N Engl J Med 362:774777. CrossRef Medline

Perez-Morales M, Alvarado-Capuleño I, López-Colomé AM, Méndez-Díaz M, Ruiz-Contreras AE, Prospéro-García O (2012) Activation of PAR1 in the lateral hypothalamus of rats enhances food intake and REMS through CB1R. Neuroreport 23:814-818. CrossRef Medline

Phelix CF, Broderick PA (1995) Light microscopic immunocytochemical evidence of converging serotonin and dopamine terminals in ventrolateral nucleus accumbens. Brain Res Bull 37:37-40. CrossRef Medline

Phillips PE, Johns JM, Lubin DA, Budygin EA, Gainetdinov RR, Lieberman JA, Wightman RM (2003) Presynaptic dopaminergic function is largely unaltered in mesolimbic and mesostriatal terminals of adult rats that were prenatally exposed to cocaine. Brain Res 961:63-72. CrossRef Medline
Pierce RC, Meil WM, Kalivas PW (1997) The NMDA antagonist, dizocilpine, enhances cocaine reinforcement without influencing mesoaccumbens dopamine transmission. Psychopharmacology 133:188-195. CrossRef Medline

Roitman MF, Stuber GD, Phillips PE, Wightman RM, Carelli RM (2004) Dopamine operates as a subsecond modulator of food seeking. J Neurosci 24:1265-1271. CrossRef Medline

Roitman MF, Wheeler RA, Carelli RM (2005) Nucleus accumbens neurons are innately tuned for rewarding and aversive taste stimuli, encode their predictors, and are linked to motor output. Neuron 45:587-597. CrossRef Medline

Schmidt HD, Famous KR, Pierce RC (2009) The limbic circuitry underlying cocaine seeking encompasses the PPTg/LDT. Eur J Neurosci 30:13581369. CrossRef Medline

Shirayama Y, Chaki S (2006) Neurochemistry of the nucleus accumbens and its relevance to depression and antidepressant action in rodents. Curr Neuropharmacol 4:277-291. CrossRef Medline

Shirazi RH, Dickson SL, Skibicka KP (2013) Gut peptide GLP-1 and its analogue, Exendin-4, decrease alcohol intake and reward. PLoS One 8:e61965. CrossRef Medline

Stefani A, Chen Q, Flores-Hernandez J, Jiao Y, Reiner A, Surmeier DJ (1998) Physiological and molecular properties of AMPA/Kainate receptors expressed by striatal medium spiny neurons. Dev Neurosci 20:242-252. CrossRef Medline

Surmeier DJ, Carrillo-Reid L, Bargas J (2011) Dopaminergic modulation of striatal neurons, circuits, and assemblies. Neuroscience 198:3-18. CrossRef Medline

Vrang N, Phifer CB, Corkern MM, Berthoud HR (2003) Gastric distension induces c-Fos in medullary GLP-1/2-containing neurons. Am J Physiol Regul Integr Comp Physiol 285:R470-R478. Medline

Zhang R, Packard BA, Tauchi M, D’Alessio DA, Herman JP (2009) Glucocorticoid regulation of preproglucagon transcription and RNA stability during stress. Proc Natl Acad Sci U S A 106:5913-5918. CrossRef Medline 